\title{
BMJ Open Regional differences in chlamydia and gonorrhoeae positivity rate among heterosexual STI clinic visitors in the Netherlands: contribution of client and regional characteristics as assessed by cross-sectional surveillance data
}

\author{
Hannelore M Götz, ${ }^{1,2,3}$ Louise AAM van Oeffelen, ${ }^{2}$ Christian J P A Hoebe, ${ }^{4,5}$
} Birgit HB van Benthem ${ }^{1}$

To cite: Götz HM, van Oeffelen LAAM, Hoebe CJPA, et al. Regional differences in chlamydia and gonorrhoeae positivity rate among heterosexual STI clinic visitors in the Netherlands: contribution of client and regional characteristics as assessed by cross-sectional surveillance data. BMJ Open 2019;9:e022793. doi:10.1136/ bmjopen-2018-022793

\section{- Prepublication history for} this paper is available online. To view these files, please visit the journal online (http://dx.doi. org/10.1136/bmjopen-2018022793).

Received 6 March 2018 Revised 10 October 2018 Accepted 23 November 2018

Check for updates

(C) Author(s) (or their employer(s)) 2019. Re-use permitted under CC BY-NC. No commercial re-use. See rights and permissions. Published by BMJ.

For numbered affiliations see end of article.

Correspondence to Dr Hannelore M Götz; hm.gotz@rotterdam.nl

\section{ABSTRACT}

Objectives To assess to what extent triage criteria, client and regional characteristics explain regional differences in Chlamydia trachomatis (Ct) and Neisseria gonorrhoeae $(\mathrm{Ng})$ positivity in sexually transmitted infection (STI) clinics.

Design Retrospective cross-sectional study on the Dutch STI surveillance database of all 24 STI clinics.

Participants STI clinic visits of heterosexual persons in 2015 with a Ct $(n=101495)$ and/or Ng test $(n=101081)$.

Primary outcome measure $\mathrm{Ct}$ and $\mathrm{Ng}$ positivity and 95\% Cl was assessed for each STI clinic. Two-level logistic regression analyses were performed to calculate the percentage change in regional variance (PCV) after adding triage criteria (model 1), other client characteristics (model 2) and regional characteristics (model 3) to the empty model. The contribution of single characteristics was determined after removing them from model 3.

Results Ct positivity was $14.9 \%$ and ranged from $12.6 \%$ to $20.0 \%$ regionally. $\mathrm{Ng}$ positivity was $1.7 \%$ and ranged from $0.8 \%$ to $3.8 \%$ regionally. For Ct, the PCV was $11.7 \%$ in model $1,32.2 \%$ in model $2 \%$ and $59.3 \%$ in model 3. Age, notified for Ct (triage), level of education (other characteristics) and regional degree of urbanisation (region) explained variance most. For $\mathrm{Ng}$, the PCV was $38.7 \%$ in model $1,61.2 \%$ in model $2 \%$ and $69.1 \%$ in model 3. Ethnicity (triage), partner in risk group, level of education and neighbourhood (other characteristics) and regional socioeconomic status (SES) explained variance most. A significant part of regional variance remained unexplained.

Conclusions Regional variance was explained by differences in client characteristics, indicating that triage and self-selection influence positivity rates in the surveillance data. Clustering of $\mathrm{Ng}$ in low SES regions additionally explained regional variance in $\mathrm{Ng}$; targeted interventions in low SES regions may assist $\mathrm{Ng}$ control. Including educational level as triage criterion is recommended. Studies incorporating prevalence data are needed to assess whether regional clustering underlies unexplained regional variance.

\section{Strengths and limitations of this study}

- The large nationwide database covering all sexually transmitted infection (STI) clinic consultations of heterosexuals with a large set of demographic and behavioural characteristics enabled us to study a range of explanatory variables for regional Chlamydia trachomatis and Neisseria gonorrhoeae positivity differences.

- By using a multilevel approach, it was possible to quantify the contribution of characteristics of STI clinic visitors to the regional variance in positivity.

- Some consultation data were incomplete for some variables of interest $(15 \%)$, which limited the generalisability of our results, although a separate analysis did not show distortion of our results.

- As we studied only STI clinic visitors and did not include patients from general practitioners, our results are not generalisable to all patients with STI.

\section{INTRODUCTION}

Chlamydia trachomatis (Ct) and Neisseria gonorrhoeae $(\mathrm{Ng})$ are the most common bacterial sexually transmitted infections (STI) among heterosexual men and women in Europe. ${ }^{1}$ In the Netherlands, Ct and $\mathrm{Ng}$ diagnostic tests are mainly performed by general practitioners (GP) and STI clinics at Public Health Services, resulting in an estimated total number of 400000 STI consultations nationwide. In 2016, it was estimated that approximately $20000 \mathrm{Ct}$ infections were diagnosed at the STI clinics and 35000 at the GP. For Ng infections these number are 6000 and 8000 , respectively. ${ }^{2}$ The GP is accessible to everyone in society and offers $\mathrm{Ct}$ and $\mathrm{Ng}$ testing on request. Laboratory tests at the GP are reimbursed by the insurance. However, a drawback 
is that the first few hundred Euros of healthcare costs are not deductible, and consequently STI tests are not always reimbursed. Public health-oriented STI clinics have been introduced nationwide in 2006 to provide confidential and free-of-charge STI testing and treatment for high-risk groups. Men who have sex with men (MSM) are eligible for regular testing at STI clinics and MSM consultations are disproportionally high at STI clinics. Heterosexuals are eligible to the STI clinic testing and treatment when they fulfil at least one of the high-risk triage criteria: notified by a partner for STI, STI-related symptoms, aged below 25 years, having a high risk for STI (eg, originating from or having a partner from an STI-endemic country or working as a commercial sex worker (CSW)) and/ or victims of sexual violence. All STI clinic visitors are routinely tested for chlamydia and gonorrhoeae, syphilis, HIV (with the possibility to opt-out) and hepatitis B/C (on indication). Previously, all visitors to the STI clinics got fully tested for Ct and $\mathrm{Ng}$ and for HIV and syphilis, but since 2015, those younger than 25 years are all tested for $\mathrm{Ct}$ and $\mathrm{Ng}$ and on indication for HIV and syphilis. ${ }^{3}$ Despite national triage criteria and test policy, there are regional differences in the number of consultations and in $\mathrm{Ct}$ and $\mathrm{Ng}$ positivity among heterosexual STI clinic visitors. Explanations might be found in variations in the proportion of certain high-risk characteristics of STI clinic visitors and in variations in regional characteristics related to positivity. Knowledge about these underlying factors might improve our understanding of the surveillance data and may possibly inform priority setting for STI clinics. In this study, we assess regional differences in Ct and Ng positivity among heterosexual STI clinic visitors between the 24 Dutch public health STI clinic regions. Our main objective is to identify explanatory factors of regional variance in $\mathrm{Ct}$ and $\mathrm{Ng}$ positivity, especially client and regional characteristics.

\section{METHODS}

\section{Data collection}

Data on STI clinic consultations and diagnoses in 2015 were obtained from the Dutch national STI surveillance database (SOAP), in which a predefined set of characteristics (including STI risk factors, diagnostic tests performed and outcomes measured) of all consultations at the 24 Dutch Public Health STI clinics is mandatory and routinely collected on a pseudonymous basis (unique numerical identifier per person which is not traceable to a person). ${ }^{4}$ The 24 STI clinics are scattered throughout the country (figure 1). In the SOAP database, all consultations of heterosexual STI clinic visitors in 2015 were selected $(n=101710)$. This database was merged with demographic data for each clients' four-digit zip code (degree of urbanisation, socioeconomic status (SES) on neighbourhood level) and for each of the 24 STI clinic regions (distribution of age, gender, non-Western origin, degree of urbanisation, SES). Demographic data on age, gender, origin and degree of urbanisation in 2015 were

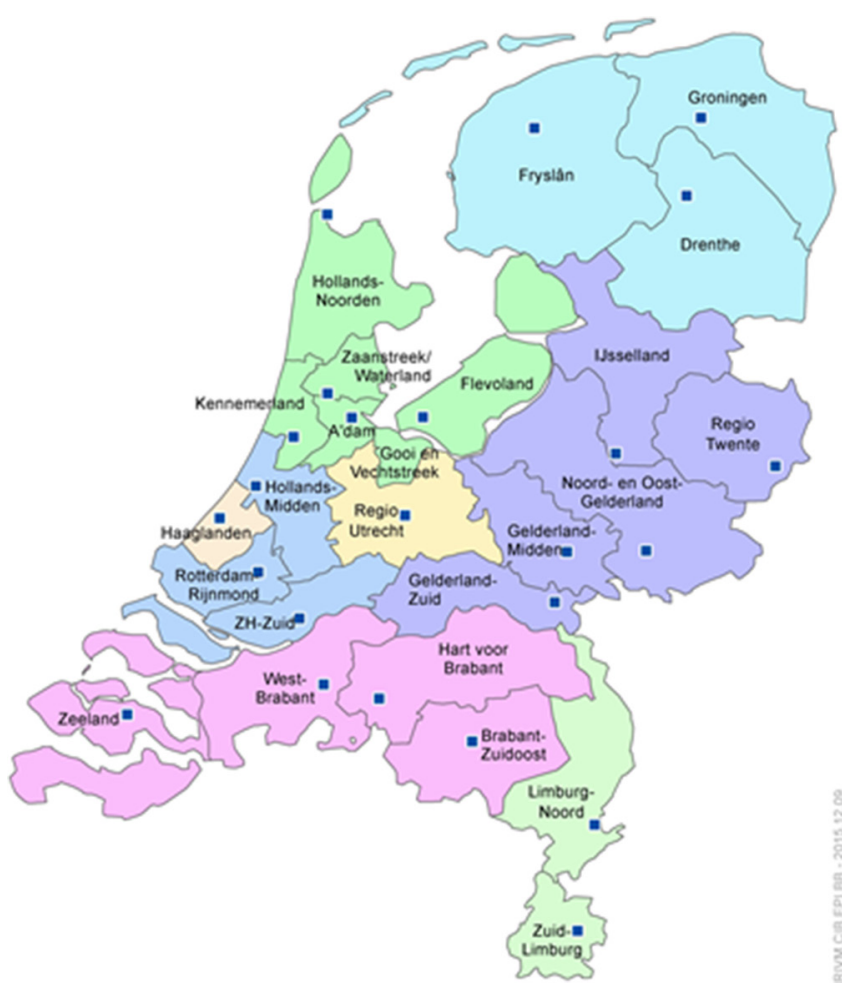

Figure 1 Sexually transmitted infection clinics in public health service regions. Blue dot is location clinic.

obtained from 'Statline' (statline.cbs.nl), an open-access platform providing freely downloadable data of Statistics Netherlands (CBS). Demographic data on SES in 2014 was requested at the Netherlands Institute for Social Research (SCP). In this merged dataset, only consultations with a $\mathrm{Ct}$ test were selected for $\mathrm{Ct}$ analyses $(\mathrm{n}=101$ 495) and only consultations with an Ng test were selected for $\mathrm{Ng}$ analyses $(\mathrm{n}=101081)$. For an overview of all variables see table 1 .

The data were routinely and pseudonymously collected for surveillance purposes and therefore the study was exempt from formal medical ethical approval under prevailing laws in the Netherlands.

\section{Explanatory variables}

Triage criteria

All triage criteria were included in the analyses: age, being notified by a sex partner for chlamydia (in Ct analyses), notified for gonorrhoea (in $\mathrm{Ng}$ analyses), STI-related symptoms, CSW, originating from an STI-endemic country, partner from risk group and $\mathrm{Ct} / \mathrm{Ng}$ /syphilis infection in the previous year. ${ }^{3}$

The continuous variable age was categorised in age groups because of the non-linear relation between age and the log odds of the outcomes chlamydia and gonorrhoea. The categories were based on the relation between age and the outcomes on a $\log$ odds scale. We chose $<20,20-24,25-29,30-34$, $\geq 35$ for Ct analyses and <20, 20-24, 25-39, $\geq 40$ years for $\mathrm{Ng}$ analyses. The presence of STI-related symptoms was unknown in $0.6 \%$ of consultations. 
Table 1 Overview source of data collection and level of analysis

\section{Statistics Institute for \\ SOAP Netherlands Social Research Categories}

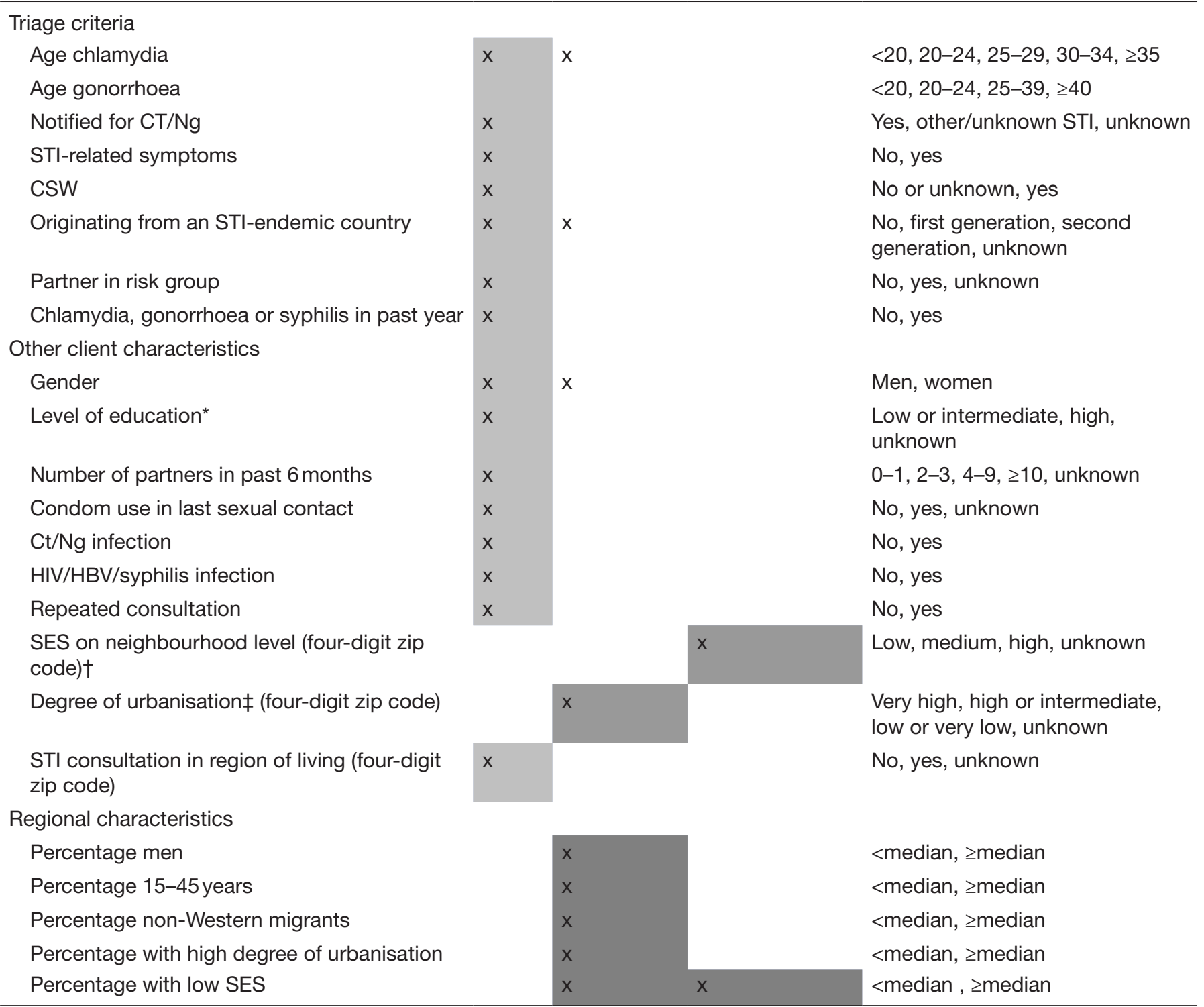

Light grey: individual level; medium grey: neighbourhood level; dark grey, regional level.

* Low/intermediate level of education: everyone who did not have education at all or who enrolled in or completed elementary school, preparatory secondary vocational education or lower general secondary education; high level of education: everyone enrolled in or who completed the school of higher general secondary education, the pre university education, university of applied sciences or university.

†SES was obtained from the SCP providing a continuous 'status score' per four-digit zip code of the entire Netherlands in 2014. This status score was based on level of education, employment and income of the inhabitants of the four-digit zip codes. The status scores were transformed into tertiles, with tertile one representing the lowest SES and tertile three representing the highest SES.

$\ddagger$ Very high degree of urbanisation: those living in neighbourhoods with $>2500$ addresses per $\mathrm{km}^{2}$; high or intermediate level of education: those living in neighbourhoods with 1000-2500 addresses per $\mathrm{km}^{2}$; low or very low degree of urbanisation: those living in neighbourhoods with $<1000$ addresses per $\mathrm{km}^{2}$.

Ct, Chlamydia trachomatis; Ng, Neisseria gonorrhoeae.

We assumed that these persons did not have symptoms and were therefore included in the category 'no symptoms'. Migratory background was based on the definition of Statistics Netherlands, which is based on country of birth of the person, mother and father. STI-endemic countries include Turkey and all countries in Africa, Asia, Eastern Europe and Latin-America. ${ }^{5}$ Categories include persons with a first-generation migratory background (person born in an STI-endemic country), and second-generation 
Open access

Table 2 Descriptive analyses of the study population

\begin{tabular}{|c|c|c|c|c|c|c|}
\hline & Male & $\%$ & Female & $\%$ & Total & $\%$ \\
\hline \multicolumn{7}{|l|}{ Age group (years) } \\
\hline$<20$ & 2175 & 6 & 8054 & 12 & 10229 & 10 \\
\hline $20-24$ & 17748 & 50 & 37339 & 57 & 55087 & 54 \\
\hline $25-29$ & 8245 & 23 & 11276 & 17 & 19521 & 19 \\
\hline $30-34$ & 3231 & 9 & 3639 & 6 & 6870 & 7 \\
\hline$>34$ & 4320 & 12 & 5683 & 9 & 10003 & 10 \\
\hline Total & 35719 & 100 & 65991 & 100 & 101710 & 100 \\
\hline Notified STI & 9501 & 27 & 10749 & 16 & 20250 & 20 \\
\hline Notified chlamydia & 7147 & 20 & 7924 & 12 & 15071 & 15 \\
\hline Notified gonorrhoea & 630 & 2 & 824 & 1 & 1454 & 1 \\
\hline Not notified & 26075 & 73 & 54962 & 83 & 81037 & 80 \\
\hline Missing & 143 & 0 & 280 & 0 & 423 & 0 \\
\hline \multicolumn{7}{|l|}{ STI-related symptoms } \\
\hline Yes & 12972 & 36 & 23052 & 35 & 36024 & 35 \\
\hline No & 22747 & 64 & 42939 & 65 & 65686 & 65 \\
\hline \multicolumn{7}{|l|}{ Originating from an STI-endemic country } \\
\hline No & 24337 & 68 & 50799 & 77 & 75136 & 74 \\
\hline Yes first generation & 4630 & 13 & 6788 & 10 & 11418 & 11 \\
\hline Yes second generation & 6695 & 19 & 8307 & 13 & 15002 & 15 \\
\hline Missing & 57 & 0 & 97 & 0 & 154 & 0 \\
\hline Partner in risk group & 8888 & 25 & 16592 & 25 & 25480 & 25 \\
\hline Commercial sex worker & 198 & 1 & 5829 & 9 & 6027 & 6 \\
\hline Chlamydia, gonorrhoea or syphilis in past year & 3550 & 10 & 7960 & 12 & 11510 & 11 \\
\hline \multicolumn{7}{|l|}{ Level of education } \\
\hline Low/intermediate & 12583 & 35 & 20885 & 32 & 33468 & 33 \\
\hline High & 21175 & 59 & 40504 & 61 & 61679 & 61 \\
\hline Unkwown & 1961 & 5 & 4602 & 7 & 6563 & 6 \\
\hline \multicolumn{7}{|l|}{ SES on neighbourhood level } \\
\hline Low & 16252 & 45 & 26862 & 41 & 43114 & 42 \\
\hline Medium & 7282 & 20 & 14223 & 22 & 21505 & 21 \\
\hline High & 10344 & 29 & 19968 & 30 & 30312 & 30 \\
\hline Unknown & 1841 & 5 & 4938 & 7 & 6779 & 7 \\
\hline \multicolumn{7}{|l|}{ Degree of urbanisation } \\
\hline Very high & 18400 & 52 & 33781 & 51 & 52181 & 51 \\
\hline High or intermediate & 11335 & 32 & 19606 & 30 & 30941 & 30 \\
\hline Low or very low & 4211 & 12 & 7780 & 12 & 11991 & 12 \\
\hline Unknown & 1773 & 5 & 4824 & 7 & 6597 & 6 \\
\hline
\end{tabular}

SES, socioeconomic status; STI, sexually transmitted infection.

migratory background (mother or father born in an STI-endemic country) and persons originating from a non-STI-endemic country. ${ }^{6}$

A partner from risk group was defined as having a partner originating from an STI-endemic country or in women as having a partner with MSM contacts. Missing data were incorporated in a separate category.
Other individual level client characteristics

The following other client characteristics were also included in the analyses: gender, level of education, number of sex partners in past 6 months, condom use in last sexual contact, infections diagnosed in the current consultation ( $\mathrm{Ng}$ infection (for Ct analyses), Ct infection (for $\mathrm{Ng}$ analyses), infection with $\mathrm{HIV} /$ hepatitis B/ 


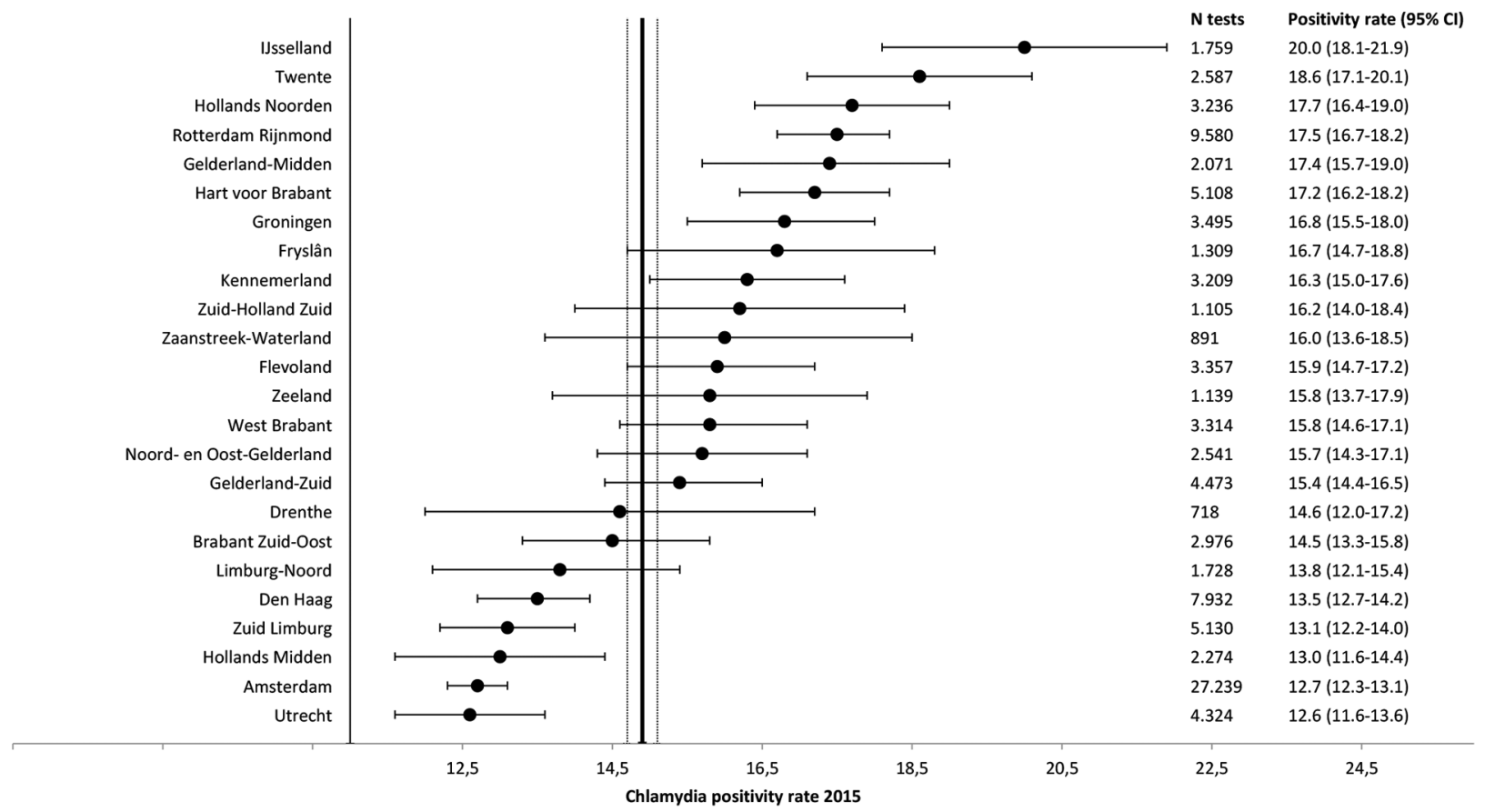

Figure 2 Chlamydia trachomatis (Ct) positivity rate by sexually transmitted infection clinic region in the Netherlands, 2015. Black dot Ct positivity rate, line depicts lower and upper limit of $95 \% \mathrm{Cl}$. Total Ct positivity rate is depicted as vertical line, and $95 \% \mathrm{Cl}$ lines on the left and right.

syphilis), repeated consultation at the same STI clinic during 2015, living in the region of the STI clinic consulted, neighbourhood SES and degree of urbanisation. The continuous variable number of sex partners was categorised in the groups $0-1,2-3,4-9$, and $\geq 10$ based on the relation between number of sex partners and the outcomes on a log odds scale. CSW who had an unknown number of partners were allocated to the group $\geq 10$. A consultation was assigned 'repeated' when the person had a previous STI clinic consultation in 2015.

\section{Client characteristics on neighbourhood level}

Degree of urbanisation of the clients' residence address was obtained from CBS per four-digit zip code and categorised in three groups (1000-2500 addresses per $\mathrm{km}^{2}$ and less or more than this range). Neighbourhood SES was obtained from SCP providing a continuous 'status score' per four-digit zip code in 2014, based on level of education, employment and income of inhabitants. ${ }^{7}$ The status scores were transformed into tertiles, with tertile one representing the lowest SES. Missing data were incorporated in a separate category.

\section{Regional characteristics of STI clinic regions}

Regional characteristics included the percentage of men, aged 15-44years (the age group to whom the majority of heterosexual STI clinic visitors belong), persons originating from an STI-endemic country (first and second generation), persons with a high degree of urbanisation and persons with a low SES within each of the 24 STI clinic regions. The median of these 24 percentages was used to construct dichotomised variables (percentage in region $<$ median, percentage in region $\geq$ median).

\section{Outcome variables}

Outcome variables were binary (positive/negative) for either Ct or $\mathrm{Ng}$ infection as indicated by a positive Nucleic Acid Amplification Test (NAAT) test at one or more anatomic locations. All analyses were performed at the level of visit for $\mathrm{Ct}$ and $\mathrm{Ng}$ separately.

\section{Statistical analyses}

Main analyses

For each region, the $\mathrm{Ct}$ and $\mathrm{Ng}$ positivity was calculated by dividing the number of positives by the number of tests performed. The corresponding 95\% CI was calculated with the following formula: $\hat{p} \pm z \sqrt{\frac{\hat{p}(1-p)}{n}}$, where $\mathrm{p}=$ proportion with positive test, $\mathrm{z}=1.96$, $\mathrm{z}$-value for a $95 \%$ CI, n=number of tests performed. 95\% CI were depicted with forest plots.

Two-level logistic regression at client level was used to analyse explanatory factors of regional differences in positivity, with consultations (level 1) nested within regions (level 2). First, a random intercept model (model 0 ) without any explanatory variables was conducted to obtain baseline regional variance $(\mathrm{V})$.

Besides model 0, three extended models were conducted with random intercepts and fixed slopes: model 1 included triage criteria, model 2 triage criteria and other individual level characteristics and model 3 triage criteria, other individual level characteristics and 


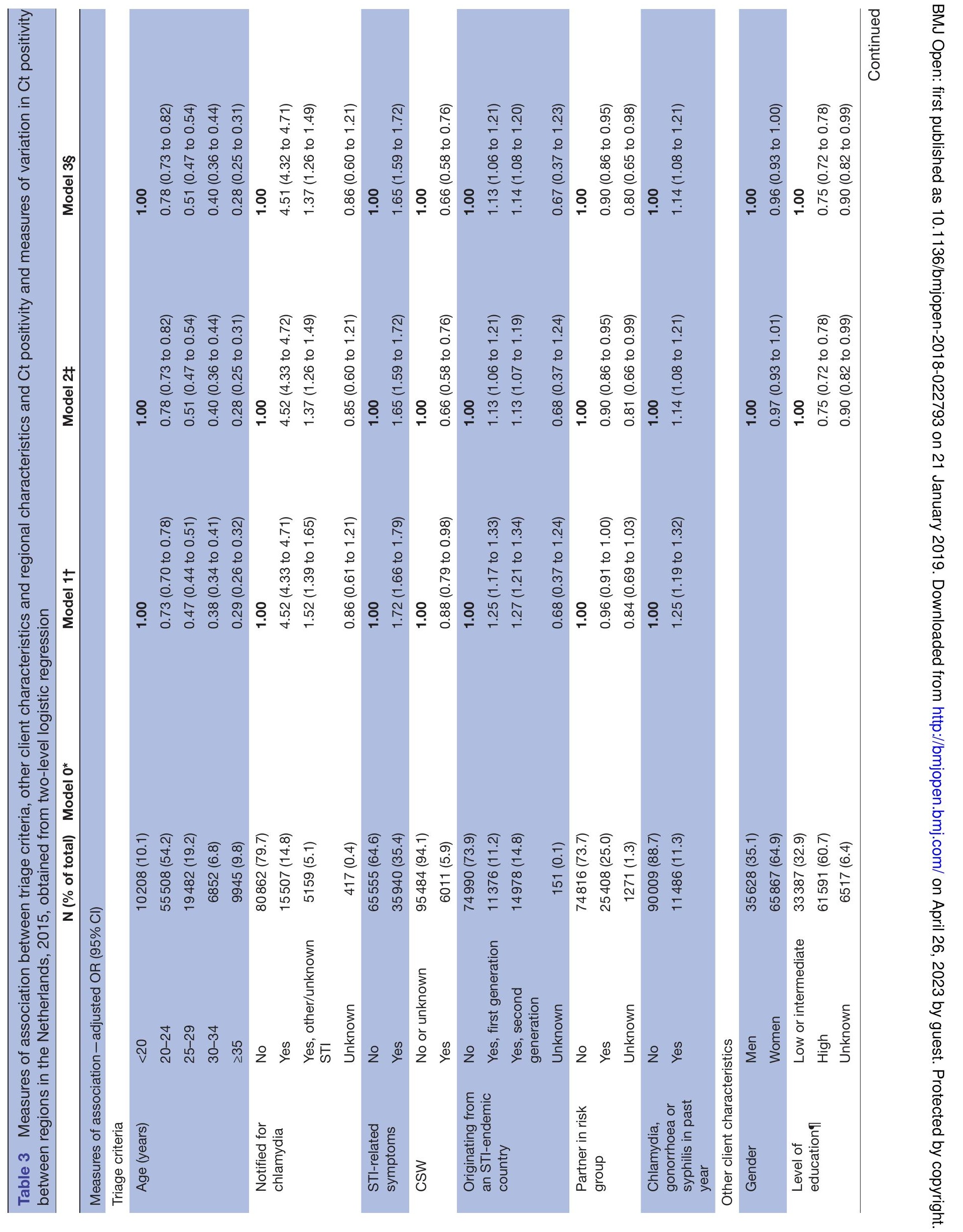




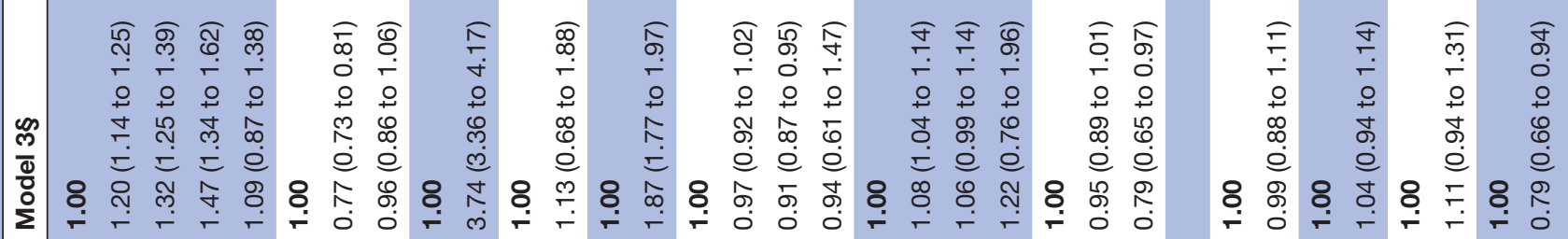

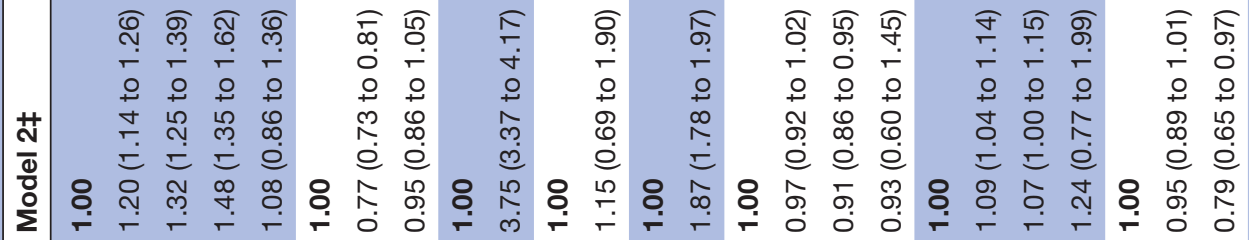

$\frac{ \pm}{\frac{5}{8}}$

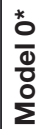

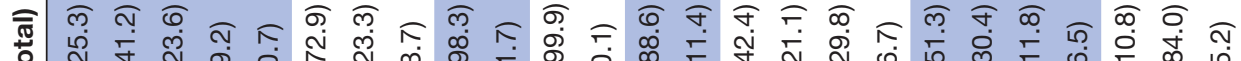

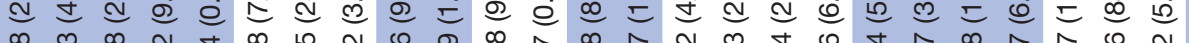

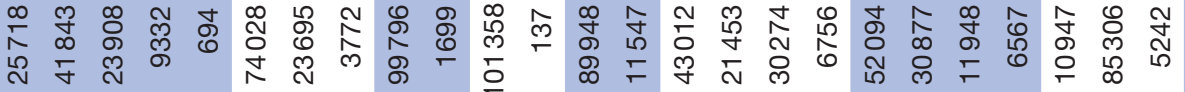

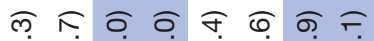
œ ले

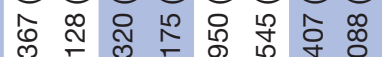
ब
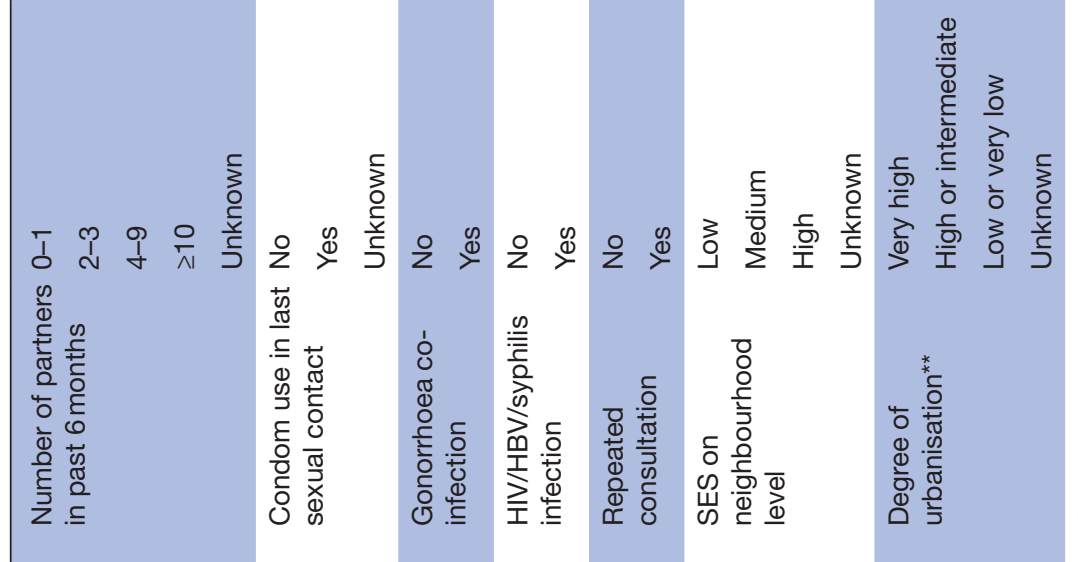

은

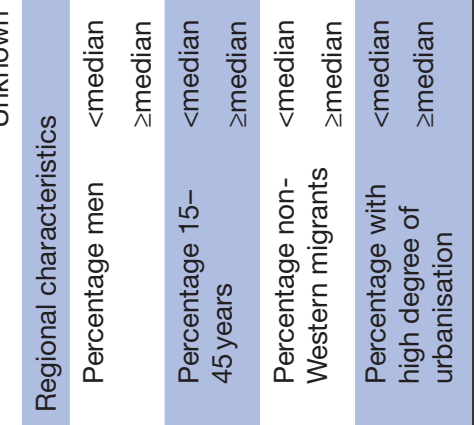




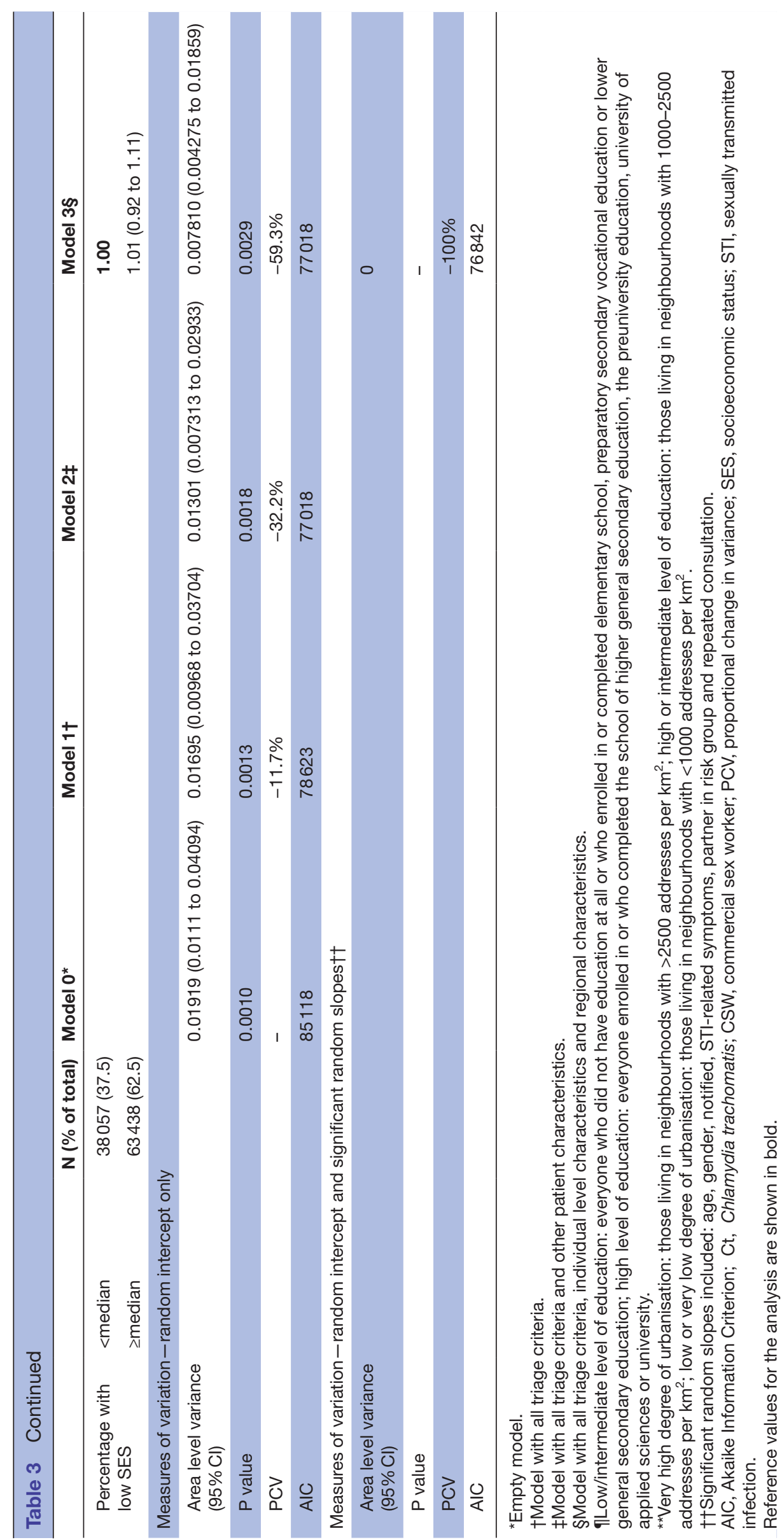


Table 4 Contribution of triage criteria, other client characteristics and regional characteristics to the regional variation in $\mathrm{Ct}$ and $\mathrm{Ng}$ positivity in the Netherlands, 2015, obtained from two-level logistic regression

\section{$\%$ contribution of} variable to variance* $^{*}$ $\mathrm{Ct} \quad \mathrm{Ng}$

\begin{tabular}{lrr}
\hline Triage criteria & & \\
Age & -38.2 & -4.3 \\
Notified for chlamydia/gonorrhoea & -15.0 & +3.1 \\
STI-related symptoms & +44.8 & +30.7 \\
CSW & +1.4 & +4.2 \\
STI-endemic migrant & +2.6 & -17.2 \\
Partner in risk group & +8.2 & -11.3 \\
Chlamydia, gonorrhoea or syphilis & +0.8 & -3.0 \\
in past year & & \\
Other client characteristics & -0.4 & -2.0 \\
\hline Gender & -15.4 & -16.1 \\
Level of education & +15.0 & +2.6 \\
Number of partners in past & & \\
6 months & +2.2 & -1.0 \\
\hline Condom use in last sexual contact & -5.0 & -0.1 \\
Gonorrhoea/chlamydia infection & +1.1 & -0.1 \\
HIV/HBV/syphilis infection & +18.0 & +2.1 \\
Repeated consultation & -2.9 & -9.4 \\
\hline $\begin{array}{l}\text { SES on neighbourhood level } \\
\text { Degree of urbanisation }\end{array}$ & +1.4 & 1.1 \\
\hline STI consultation in region of living & -1.1 & -1.4 \\
\hline
\end{tabular}

Regional characteristics

\begin{tabular}{|c|c|c|}
\hline Percentage men & 0.0 & -0.2 \\
\hline $\begin{array}{l}\text { Percentage between } 15 \text { and } \\
45 \text { years }\end{array}$ & -1.1 & +0.2 \\
\hline Percentage non-Western migrants & -5.8 & -0.5 \\
\hline $\begin{array}{l}\text { Percentage with high degree of } \\
\text { urbanisation }\end{array}$ & -24.0 & -1.5 \\
\hline Percentage with low SES & +1.2 & -18.6 \\
\hline
\end{tabular}

*Percentage contribution of variable to regional variance. Separate variables are deleted from full model and variance is compared with variance in full model. Percentage contribution $=-($ (variance full model without one variable-variance full model)/variance full model without one variable) $\times 100 \%$. This is a different measure than the PCV; therefore, these percentages do not add up to the total PCV of the full model.

Ct, Chlamydia trachomatis; CSW, commercial sex worker; Ng, Neisseria gonorrhoeae; PCV, proportional change in variance; SES, socioeconomic status; STI, sexually transmitted infection.

regional characteristics. For every model, the association between characteristics and outcomes were computed as adjusted ORs with $95 \%$ CI. Furthermore, the regional variance was noted. The proportional change in variance (PCV) was calculated to assess the extent to which the characteristics in the model explained regional variance. ${ }^{8}$
$\mathrm{PCV}_{\mathrm{i}}=\frac{\mathrm{V}_{0}-\mathrm{V}_{\mathrm{i}}}{\mathrm{V}_{0}}$, where $\mathrm{V}_{0}$ is the regional variance of model $0, V_{i}$ is regional variance of model $i$ and $i=2,3$.

To investigate which characteristics contributed most to regional variance, the percentage of contribution was computed for each jariable separately.

$\%$ contribution $=\frac{\mathrm{V}_{4}-\mathrm{V}_{3,(.)}}{\mathrm{V}_{3,(-\mathrm{k})}}$, where $\mathrm{V}_{3,(-\mathrm{k})}$ is the regional variance of model 3 without characteristic $\mathrm{k}, \mathrm{V}_{3,(.)}$ to the variance of model 3 with all characteristics.

Cleaning and merging of datasets and calculation of positivity rates were performed with SPSS V.24.0. Two-level logistic regression analyses were performed with SAS V.9.4. Forest plots were produced with Microsoft Excel 2010.

\section{Additional analyses}

To examine whether the associations between client characteristics and the outcomes differ between regions, model 3 was extended with random slopes for all client characteristics. With a backward selection procedure, only statistically significant $(\mathrm{p}<0.05)$ random slopes were included in the model. Subsequently, the PCV was calculated to investigate into what extent random slopes additionally explained regional variance. Furthermore, all analyses were repeated after missing values were imputed using multiple imputation (data not shown).

\section{Patient and public involvement}

Patients and or public were not involved in this retrospective study based on STI surveillance data.

\section{RESULTS}

The characteristics of the study population are shown in table 2 .

\section{Ct positivity}

Ct positivity was $14.9 \%$ (95\% CI $14.7 \%$ to $15.1 \%$ ) and ranged from $12.6 \%$ (95\% CI $11.6 \%$ to $13.6 \%$ ) to $20.0 \%$ (95\% CI $18.1 \%$ to $21.9 \%$ ) regionally (figure 2). After including triage criteria, $11.7 \%$ of regional variance was explained (table 3). In this model, almost all triage criteria were statistically significantly associated with Ct, except for CSW and partner in risk group. After including other client characteristics, $32.2 \%$ of regional variance was explained. The triage criteria CSW and partner in risk group also became independently associated with Ct: CSW and those with a partner in risk group had lower Ct positivity. Other patient characteristics associated with Ct were level of education, number of partners in past 6 months, condom use in last sexual contact, $\mathrm{Ng}$ co-infection, repeated consultation, neighbourhood SES and degree of urbanisation. After including regional characteristics, $59.3 \%$ of regional variance was explained. The only regional characteristic independently associated with $\mathrm{Ct}$ was degree of urbanisation: those living in highly urbanised regions had lower Ct positivity when visiting the STI clinic. 


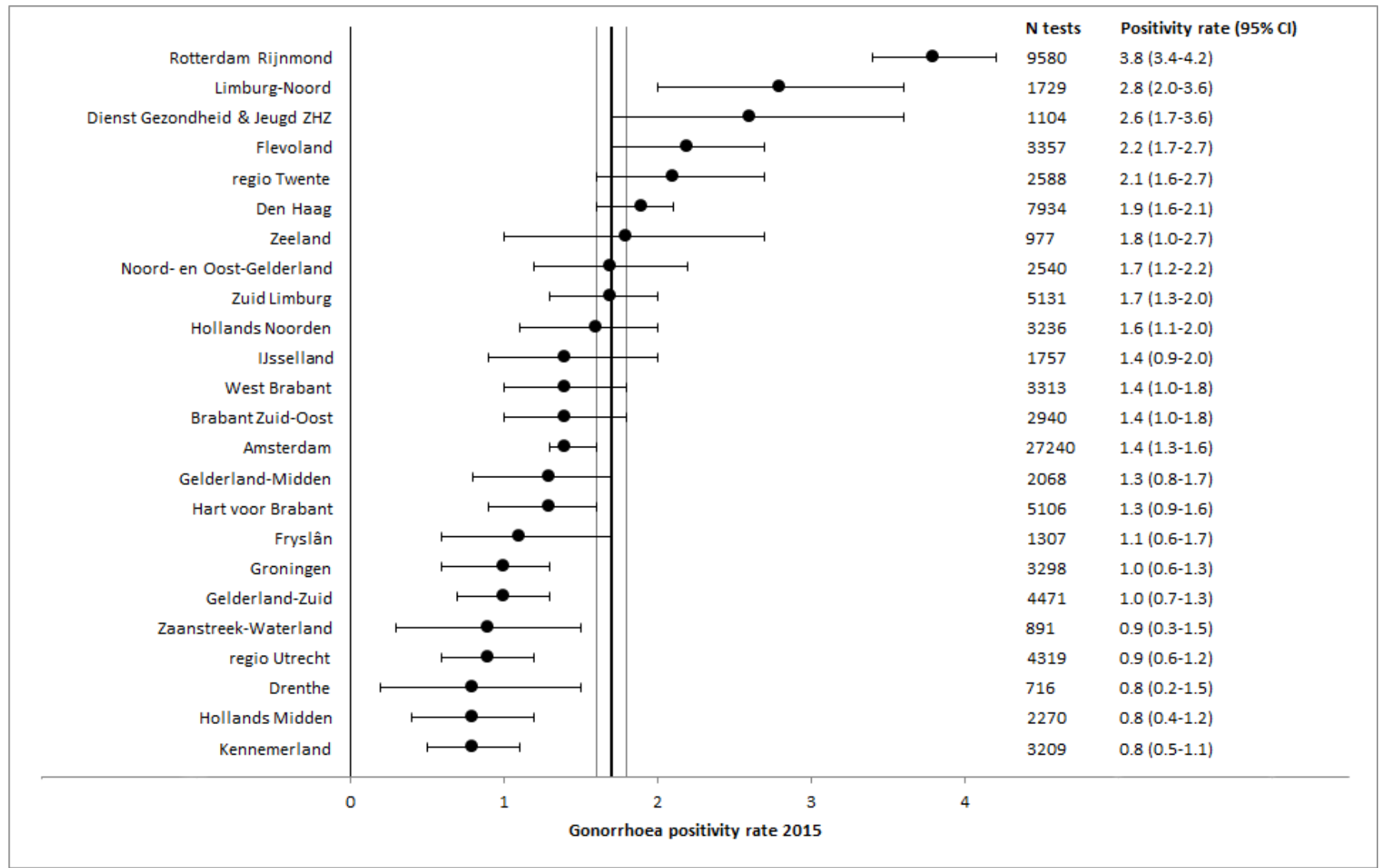

Figure 3 Neisseria gonorrhoeae (Ng) positivity by sexually transmitted infection clinic region in the Netherlands, 2015. Black dot $\mathrm{Ng}$ positivity rate, line depicts lower and upper limit of $95 \% \mathrm{Cl}$. Total $\mathrm{Ng}$ positivity rate is depicted as vertical line, and $95 \% \mathrm{Cl}$ lines on the left and right.

The variables age, being notified for Ct, level of education and regional degree of urbanisation contributed most to regional variance, respectively $-38.2 \%$, $-15.0 \%,-15.4 \%$ and $-24.0 \%$ (table 4 ). On the other hand, STI-related symptoms, number of partners in past 6 months and repeated consultation increased regional variance after including them in the model, respectively $+44.8 \%,+15.0 \%$ and $+18.0 \%$.

There were significant random slopes for age, notified, STI-related symptoms, partner in risk group, gender and repeated consultation. After adding these random slopes to model 3, the PCV increased to $100 \%$ (table 3).

\section{$\mathrm{Ng}$ positivity}

$\mathrm{Ng}$ positivity was $1.7 \%$ (95\% CI $1.6 \%$ to $1.8 \%$ ) and ranged from $0.8 \%$ (95\% CI $0.5 \%$ to $1.1 \%$ ) to $3.8 \%$ (95\% CI $3.4 \%$ to $4.2 \%$ ) regionally (figure 3 ). After including triage criteria, $38.7 \%$ of regional variance was explained. All triage criteria were statistically significantly associated with $\mathrm{Ng}$ (table 5). After adding other client characteristics, $61.2 \%$ of regional variance was explained. Level of education, number of partners in past 6 months, Ct infection, repeated consultation, neighbourhood SES and living in region of STI clinic consultation were associated with $\mathrm{Ng}$. After adding regional characteristics, $69.1 \%$ of regional variance was explained. One regional characteristic independently associated with $\mathrm{Ng}$ was SES: those living in 'low SES regions' (defined as SES $<$ median) had a borderline statistically significant higher $\mathrm{Ng}$ positivity when visiting the STI clinic.

The variables STI-endemic migrant, partner in risk group, level of education and SES on neighbourhood and regional level contributed most to regional variance, respectively $-17.2 \%,-11.3 \%,-16.1 \%,-9.4 \%$ and $-18.6 \%$ (table 4 ). On the other hand, STI-related symptoms increased regional variance after including it in the model $(+30.7 \%)$.

There was a significant random slope for age. After adding this random slope to model 3, the PCV increased from $69.1 \%$ to $87.2 \%$, with no statistically significant regional variance left (table 5 ).

\section{DISCUSSION \\ Main findings}

Our study showed moderate statistically significant regional variance in $\mathrm{Ct}$ and $\mathrm{Ng}$ positivity among Dutch heterosexual STI clinic visitors. For Ct, about one-third of regional variance was explained by differences in client characteristics (mainly age, being notified for $\mathrm{Ct}$ and level of education), and $69 \%$ when adding regional characteristics (mainly low degree of urbanisation). For $\mathrm{Ng}$, about two-thirds of regional variance was explained by 


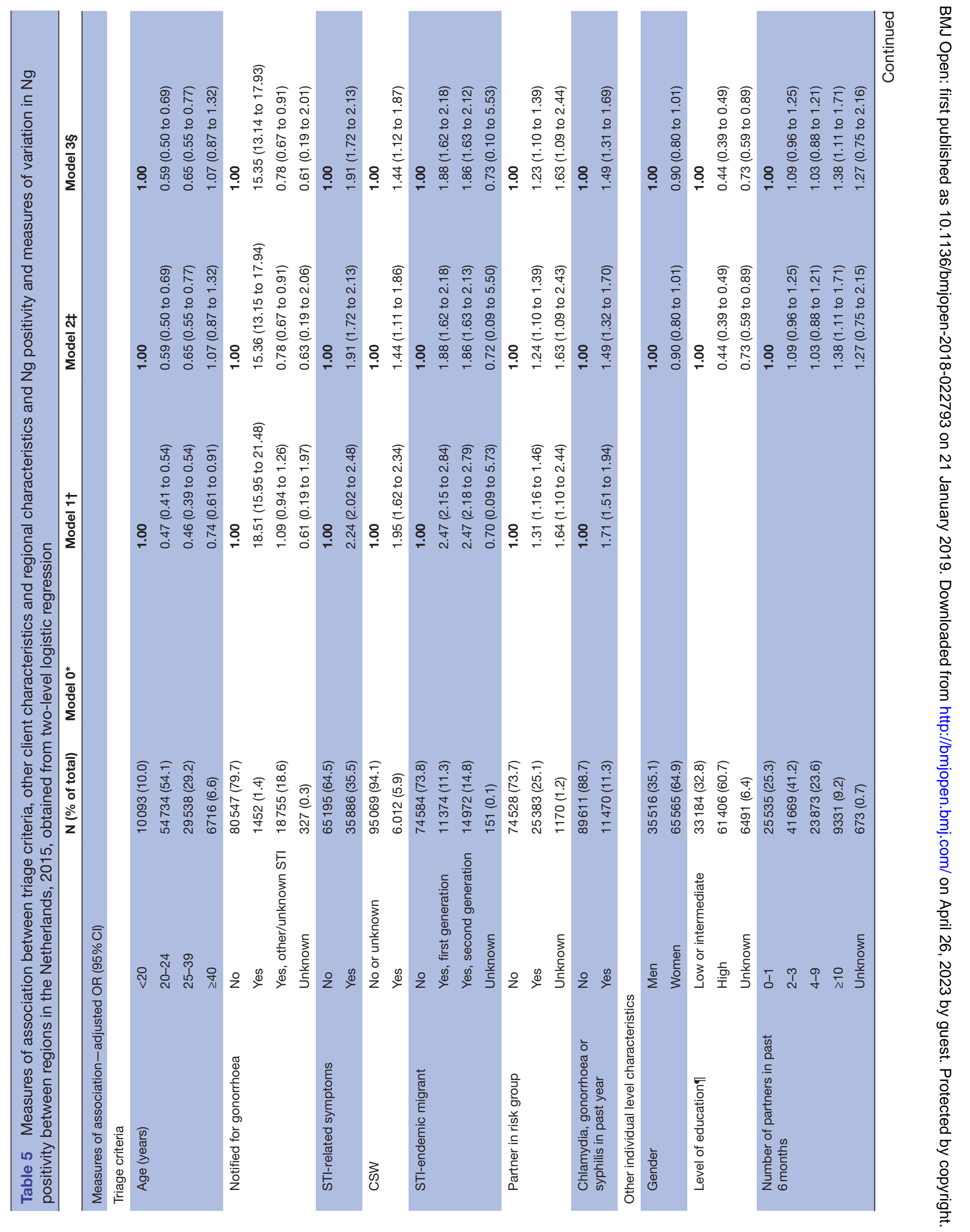




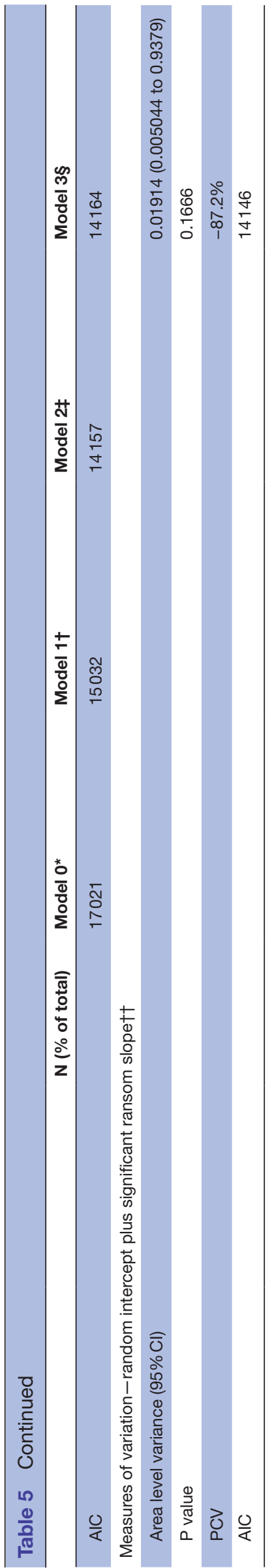

differences in client characteristics (mainly STI-endemic migrant, partner from risk group, level of education and neighbourhood SES), and 59\% when adding regional characteristics (mainly low SES).

\section{Regional variance explained by client level characteristics}

In order to contribute to regional variance, a client characteristic has to fulfil the following conditions: 1) the characteristic has to be related to the outcome, 2) the proportion of the characteristic has to vary between regions and 3) the prevalence of the characteristic has to be sufficiently high. The client characteristics reducing variance most are strongly associated with $\mathrm{Ct}$ and $\mathrm{Ng}$ positivity, as reported previously. ${ }^{9-16}$ Furthermore, the proportion of visitors with these characteristics is higher in regions with higher positivity. Consequently, correcting for these variables decreased regional variance. Some client characteristics however increased regional variance when included in the model, mainly STI-related symptoms. This indicates that the proportion of visitors with STI-related symptoms in regions with higher positivity is lower. The reasons behind different proportions of client characteristics between regions might be related to STI clinic location by familiarity with and accessibility of STI clinics, balance between availability of consultations and requests and subsequent stringent triage application, and differences in demography of STI clinics adherence area like urbanisation and ethnicity.

The characteristics contributing most to regional variance differed between $\mathrm{Ct}$ and $\mathrm{Ng}$, mainly because of varying associations between these characteristics and the two outcomes. For example, STI-endemic migrant, partner in risk group and neighbourhood SES were more strongly related to $\mathrm{Ng}$ positivity than to Ct positivity. Furthermore, although being notified for Ng was strongly associated with $\mathrm{Ng}$ positivity, the prevalence of $\mathrm{Ng}$ notifications was too low to influence regional variance.

Low/intermediate level of education was independently associated with Ct and/or $\mathrm{Ng}$ positivity and contributed strongly to regional variance, which confirms previous studies. ${ }^{1517}$ We advise to include education as a triage criterion into the STI clinic access policy, as persons with low/intermediate education are under-represented at STI clinics (33\%) compared with $70 \%$ in the general Dutch population. ${ }^{4}$

\section{Regional variance explained by regional characteristics}

Regional SES explained part of regional variance in $\mathrm{Ng}$ positivity. Living in a low SES region increased $\mathrm{Ng}$ positivity independent of neighbourhood SES and level of education. This suggests that there is clustering of $\mathrm{Ng}$ among heterosexuals within low SES neighbourhoods and regions. Previous studies also found clustering of $\mathrm{Ng}$ within low SES regions and among migrant populations. ${ }^{9-11} 1618$ Neighbourhood and regional SES had no influence on regional variance in Ct positivity, as is also described previously. ${ }^{19}$ However, regional degree of urbanisation was an important contributor to regional variance 
in Ct. Living in urbanised regions decreased Ct positivity at STI clinics. This is apparently in contrast to previous Dutch studies in which a high degree of urbanisation was related to higher Ct prevalence. ${ }^{1720}$ A large proportion of visitors is from urbanised areas where most STI clinics are located. Visitors from low urbanised areas visit STI clinics less frequently but those that do visit the STI clinic have a higher Ct positivity rate possibly due to effective self-selection. Additional analyses showed that high urbanised regions had lower Ct positivity rates among those notified for Ct and among those with STI-related symptoms than low urbanised regions (not shown). Possibly, inhabitants of urbanised regions are more familiar with and have easier access to STI clinics.

\section{Unexplained regional variance}

Part of regional variance remained unexplained. After including significant random slopes in model 3, all regional variance was explained. The differential association between these characteristics and infection between regions explained all remaining regional variance. This implies that $\mathrm{Ct} / \mathrm{Ng}$ risk of an STI clinic visitor differs between regions, even when client characteristics are similar. This may be caused by differences in the self-selection of persons visiting the STI clinic and in prioritising practices at STI clinics between regions, but it may also reflect real regional differences. Previous studies reported strong evidence for spatial $\mathrm{Ng}$ clustering in the UK and the USA, independent of sociodemographic regional factors. ${ }^{10} 18$ 21-24 Also regional Ct clusters have been reported, although they were less strong and more diffuse compared with Ng clusters. ${ }^{25}$ Studies incorporating prevalence data are needed to assess whether regional clustering of $\mathrm{Ct}$ and $\mathrm{Ng}$ is present in the Netherlands.

\section{Strengths and limitations}

Analysing a nationwide database with a large set of demographic and behavioural characteristics enabled us to study a range of explanatory variables. By using a multilevel approach, it was possible to quantify the contribution of characteristics of STI clinic visitors to the regional variance in positivity. To the best of our knowledge, this has not been done before. There are also some limitations to address. First, in $15 \%$ of consultations data were incomplete for some variables of interest, varying between $0.1 \%$ and $6.7 \%$. Missing data were incorporated as a separate group, which could have distorted results. However, missing data were imputed using multiple imputation, and results remained robust (not shown). ${ }^{26}$ Second our study is limited to STI clinic visitors, and did not account for STI related consultations at GP practices. STI visitors are at high risk, partially due to self-selection and due to triage, and therefore do not reflect the Dutch population. ${ }^{27} 28$ As our aim was to explain regional variance within the STI clinic data and not to investigate the real positivity, this is in fact not limiting the results of our study. Third, although a large set of characteristics was available, residual confounding remains possible.

\section{CONCLUSION AND RECOMMENDATIONS}

We found statistically significant regional variance in Ct and $\mathrm{Ng}$ positivity among Dutch heterosexual STI clinic visitors. Regional variance was explained by differences in client characteristics, indicating that triage and self-selection influence positivity rates in the surveillance data. Client characteristics explained a larger part of regional variance in $\mathrm{Ng}$ than in $\mathrm{Ct}$ suggesting that $\mathrm{Ng}$ is more concentrated in high-risk persons. ${ }^{29}$ Furthermore, our results indicate $\mathrm{Ng}$ clustering among heterosexuals within low SES neighbourhoods and regions; targeted interventions in low SES regions may therefore be valuable for $\mathrm{Ng}$ control. STI clinics might strengthen their efforts to include young lower educated heterosexuals to improve Ct control, and also increase their efforts in reaching more low educated persons from low SES and/or migrant origin in case of $\mathrm{Ng}$ control. Although prevalence studies are known to have methodological and practical challenges and are scarce, they are needed to assess whether real regional differences appear. Furthermore, each STI clinic should investigate the characteristics of their clients at highest risk to develop targeted prioritising policy and ideally combine this information with data from GP patients to get a complete regional perspective.

\section{Author affiliations}

${ }^{1}$ Centre for Infectious Disease Control, National Institute for Public Health and the Environment, Rotterdam, The Netherlands

${ }^{2}$ Department of Infectious Disease Control, Municipal Public Health Service Rotterdam-Rijnmond, Rotterdam, The Netherlands

${ }^{3}$ Department of Public Health, Erasmus MC-University Medical Center Rotterdam, Rotterdam, The Netherlands

${ }^{4}$ Department of Sexual Health, Infectious Diseases and Environmental Health, Public Health Service South Limburg, Geleen, The Netherlands

${ }^{5}$ Department of Medical Microbiology, Maastricht University Medical Centre, Care and Public Health Research Institute, Maastricht, The Netherlands

Acknowledgements The authors would like to thank the co-workers of the 24 Dutch STI clinics for the thorough data entry of all consultations. The authors would also like to thank Dr Jan van de Kassteele and Dr David van Klaveren for their statistical advice and to Dr Maarten Schipper for performing the multiple imputation.

Contributors HG initiated the study, helped interpreting the data and drafted and revised the manuscript. Lv0 initiated the study, analysed and interpreted the data and drafted the manuscript. BvB and CJPAH helped interpreting the data and revised the manuscript draft. All authors read and approved the final manuscript.

Funding The authors have not declared a specific grant for this research from any funding agency in the public, commercial or not-for-profit sectors.

Competing interests None declared.

Patient consent for publication Not required.

Provenance and peer review Not commissioned; externally peer reviewed.

Data sharing statement Results of analyses on the imputed datasets are available on request from the corresponding author after permission of the registration committee for the Dutch STI clinic database. The Corresponding Author has the right to grant on behalf of all authors and does grant on behalf of all authors, an exclusive licence (or non-exclusive for government employees) on a worldwide basis to the BMJ Publishing Group Ltd (BMJPGL) to permit this article (if accepted) to be published in BMJ open and any other BMJPGL products and sublicences such use and exploit all subsidiary rights, as set out in our licence http://group.bmj.com/ products/journals/instructions-for-author.

Open access This is an open access article distributed in accordance with the Creative Commons Attribution Non Commercial (CC BY-NC 4.0) license, which 
permits others to distribute, remix, adapt, build upon this work non-commercially, and license their derivative works on different terms, provided the original work is properly cited, appropriate credit is given, any changes made indicated, and the use is non-commercial. See: http://creativecommons.org/licenses/by-nc/4.0/.

\section{REFERENCES}

1. Spiteri G. Sexually transmitted infections in Europe 2013. Stockholm: ECDC, 2015

2. Visser M, van Aar F, van Oeffelen A, et al. Sexually transmitted infections in the Netherlands in 2016. Bilthoven: RIVM, 2017.

3. Draaiboek Consult seksuele gezondheid - Deeldraaiboek 6 : Testbeleid. 2015. http://www.rivm.nl/dsresource?objectid=94096dc6 ae14-49fb-ad8a-06f10883bc14\&type=pdf\&disposition=inline: soaLOI

4. Visser M, van Aar F, van Oeffelen AAM, et al. Sexually transmitted infections including HIV, in the Netherlands in 2016. Bilthoven, The Netherlands: RIVM, 2017.

5. RIVM. Lijst soa/hiv-endemische landen. Bilthoven: RIVM, 2012.

6. Stronks K, Kulu-Glasgow I, Agyemang C. The utility of 'country of birth' for the classification of ethnic groups in health research: the Dutch experience. Ethn Health 2009;14:255-69.

7. Knol FA. Van hoog naar laag; van laag naar hoog: Den Haag Sociaal Cultureel Planbureau, 2009.

8. Merlo J, Yang M, Chaix B, et al. A brief conceptual tutorial on multilevel analysis in social epidemiology: investigating contextual phenomena in different groups of people. J Epidemiol Community Health 2005;59:729-36.

9. Lacey CJ, Merrick DW, Bensley DC, et al. Analysis of the sociodemography of gonorrhoea in Leeds, 1989-93. BMJ 1997;314:1715-8.

10. Sullivan AB, Gesink DC, Brown P, et al. Are neighborhood sociocultural factors influencing the spatial pattern of gonorrhea in North Carolina? Ann Epidemiol 2011;21:245-52.

11. Du P, McNutt LA, O'Campo $P$, et al. Changes in community socioeconomic status and racial distribution associated with gonorrhea rates: an analysis at the community level. Sex Transm Dis 2009;36:430-8

12. Hickman $M$, Judd $A$, Maguire $H$, et al. Incidence of gonorrhoea diagnosed in GUM clinics in South Thames (west) region. Sex Transm Infect 1999;75:306-11.

13. McDonagh P, Ryder N, McNulty AM, et al. Neisseria gonorrhoeae infection in urban Sydney women: prevalence and predictors. Sex Health 2009;6:241-4.

14. James AB, Geisler WM. Predictors of high chlamydia and gonorrhea positivity rates among men in the southern United States. J Natl Med Assoc 2012;104(1-2):20-7.
15. Corsenac $P$, Noël M, Rouchon B, et al. Prevalence and sociodemographic risk factors of chlamydia, gonorrhoea and syphilis: a national multicentre STI survey in New Caledonia, 2012. BMJ Open 2015;5:e007691.

16. Rice RJ, Roberts PL, Handsfield HH, et al. Sociodemographic distribution of gonorrhea incidence: implications for prevention and behavioral research. Am J Public Health 1991;81:1252-8.

17. van Bergen J, Götz HM, Richardus JH, et al. Prevalence of urogenital Chlamydia trachomatis increases significantly with level of urbanisation and suggests targeted screening approaches: results from the first national population based study in the Netherlands. Sex Transm Infect 2005;81:17-23.

18. Le Polain De Waroux O, Harris RJ, Hughes G, et al. The epidemiology of gonorrhoea in London: a Bayesian spatial modelling approach. Epidemiol Infect 2014;142:211-20.

19. van Klaveren D, Götz HM, Op de Coul EL, et al. Prediction of Chlamydia trachomatis infection to facilitate selective screening on population and individual level: a cross-sectional study of a population-based screening programme. Sex Transm Infect 2016;92:433-40.

20. Götz HM, van Bergen JE, Veldhuijzen IK, et al. A prediction rule for selective screening of Chlamydia trachomatis infection. Sex Transm Infect 2005;81:24-30.

21. Jennings JM, Curriero FC, Celentano D, et al. Geographic identification of high gonorrhea transmission areas in Baltimore, Maryland. Am J Epidemiol 2005;161:73-80.

22. Law DC, Serre ML, Christakos G, et al. Spatial analysis and mapping of sexually transmitted diseases to optimise intervention and prevention strategies. Sex Transm Infect 2004;80:294-9.

23. Risley CL, Ward H, Choudhury B, et al. Geographical and demographic clustering of gonorrhoea in London. Sex Transm Infect 2007:83:481-7.

24. Shaw SY, Nowicki DL, Schillberg E, et al. Epidemiology of incident chlamydia and gonorrhoea infections and population attributable fractions associated with living in the inner-core of Winnipeg, Canada. Int J STD AIDS 2017;28:550-7.

25. Schleihauf E, Watkins RE, Plant AJ. Heterogeneity in the spatial distribution of bacterial sexually transmitted infections. Sex Transm Infect 2009;85:45-9.

26. Sterne JA, White IR, Carlin JB, et al. Multiple imputation for missing data in epidemiological and clinical research: potential and pitfalls. BMJ 2009;338:b2393.

27. de Graaf H, Kruijer H, van Acker J, et al. Seks onder je 25e 2: Seksuele gezondheid van jongeren in Nederland anno 2012. Delft: Eburon, 2012.

28. Creighton S, Edwards S, Welch J, et al. News from the frontline: sexually transmitted infections in teenagers attending a genitourinary clinic in south east London. Sex Transm Infect 2002;78:349-51.

29. Jolly AM, Wylie JL. Gonorrhoea and chlamydia core groups and sexual networks in Manitoba Sex Transm Infect 2002;78:i145-51. 